\title{
The D-CAPM: The Case of Great Britain and France
}

\author{
Nikolaos Artavanis \\ Pamplin College of Business \\ Virginia Tech \\ Blacksburg, VA 24061 \\ E-mail: nartavan@vt.edu \\ Prof. George Diacogiannis \\ Department of Financial Management and Banking \\ University of Piraeus, Greece \\ School of Management, University of Bath, UK, Visiting scholar \\ E-mail: gdiak@unipi.gr. \\ John Mylonakis \\ 10 Nikiforou str., Glyfada \\ 16675 , Athens, Greece \\ E-mail: imylonakis@vodafone.net.gr
}

\begin{abstract}
In recent years the mean-semivariance has been proposed in place of the mean-variance as an alternative approach to portfolio analysis since different investors assign a lower weight to positive deviations from the mean than to negative ones. The present work investigates empirically the relationship between risk and return in a downside risk framework and in a regular risk framework by utilizing returns of securities traded on the London Stock Exchange and Paris Stock Exchange. The results reveal that in many cases the downside risk measures are equivalent or better in explaining mean returns than the regular risk measures. The paper also introduces a new risk-return relation that holds when the distribution of security returns are normal and the market index lies inside the semi-deviation-expected return efficient frontier. The existence of this model may provide a possible explanation of the empirical results included in this work. Finally, it is argued that for skewed distributions of security returns it may be better to employ a three parameter asset pricing than the mean semivariance risk-return relation.
\end{abstract}

Keywords: Variance, Semivariance, Regular Beta, Downside Beta

JEL Classification code: G11

\section{Introduction}

In the pioneering work on portfolio analysis Markowitz (1959) offered the possibility of measuring portfolio risk using the semivariance of returns instead of the variance of returns. The variance treats deviations below the mean and deviations above the mean in the same way whereas investors assign a lower weight to positive deviations than to negative ones. This argument can be used to justify the replacement of the variance with the semivariance. The semivariance of security returns measures the dispersion of the distribution of returns that fall below a pre-specified target rate of return.

Hogan and Warren (1974), as well as, Bawa and Lindenberg (1977) developed the mean - semivariance CAPM (MS-CAPM) which presents the expected return of a security as an exact linear function of its downside beta computed with respect to the market portfolio. The numerator of the downside beta is the cosemivariance between security and market returns with the return of the risk free rate as the target return. The denominator is the semivariance of returns on the market portfolio with respect to the risk-free rate. The downside beta shows the co-movements with the market portfolio in a falling market. The MS CAPM (the mean-variance CAPM (MV-CAPM)) predicts that the value-weighted market portfolio of risky securities is efficient in the space of semi-deviation and expected return (standard deviation and expected return). The main difference between the MS-CAPM and the MV-CAPM is that the former relies on the risk measures of semivariance and downside beta 
while the latter uses the risk measures of variance and regular beta. The MS portfolio analysis, also, assumes that investors are risk averse for all returns below the target rate of return and risk-natural for all returns above the target rate of return. The MV portfolio analysis makes the assumption that investors are risk averse over all returns. However, such a difference is dependent on the type of the security return distribution. If the distributions of returns are normal, the downside beta and the regular beta are identical. On the other hand if the distributions of returns are skewed, the downside beta and the regular beta diverge.

Early empirical investigations of the validity of the MS-CAPM include Jahankhani (1976), Harlow and Rao (1989), and Nantell, Price and Price (1982). Interestingly, the MS-CAPM seems to capture better the cross-section of stock returns than the MV- CAPM (Harlow and Rao, 1989; Post and Van Vliet, 2004). Estrada (2000) and Harvey (2000) produced evidence revealing the superiority of semideviation to explain the cross section of emerging market returns. Estrada (2002c) introduced the downside CAPM (D-CAPM), which is based on a mean-semivariance behavior assumption as opposed to the CAPM mean-variance behaviour assumption. Using the Morgan Stanley Capital Indices database of Emerging Markets presents evidence depicting the superiority of the downside beta over the regular beta in explaining the cross sectional of security mean returns.

The contribution of this paper is twofold. First it employs returns of securities traded on the London Stock Exchange and Paris Stock Exchange and investigates empirically whether the semi-deviation and the downside beta are superior in explaining expected returns as compared with the standard deviation and the regular beta, respectively. This investigation utilizes the methodology of Estrada (2002c). The second contribution is theoretical. It introduces a new risk-return relation that holds when the distribution of security returns are normal and the market index lies inside the semi-deviation-expected return efficient frontier. Using the new model the paper provides a possible explanation of the empirical results included in the present work and casts some doubts on the utilization of the MS CAPM in explaining security expected returns.

The remaining contents of the paper are organized as follows. Section I presents a review of the previous studies related to the return interval effect on estimated betas. Section II describes the data employed in the empirical tests and the research methodology. Section III discusses the empirical results obtained and offers a possible explanation of the results. Finally, Section IV contains a summary of the paper.

\section{Past Literature Review}

Hogan and Waren (1974) used an expected return standard semivariance analysis and derived a security market line analogous to the security market line of Sharpe (1964) and Lintner (1965) that employs an expected return variance framework. Markowitz (1959, ch. 9) offered the possibility of using the semivariance of returns instead of the variance of returns as a measure of portfolio risk. Their equilibrium model can be presented as follows (it is assumed that the market portfolio is expected return-semivariance efficient):

$$
E\left(R_{j}\right)=R_{f}+\left[E\left(R_{M}\right)-R_{f}\right] \frac{\operatorname{csv}\left(R_{j}, R_{M}\right)}{\operatorname{sv}\left(R_{M}\right)}
$$

where $E[]=$. the expected value operator, ${ }^{E}\left(R_{j}\right)=$ the expected return of a security or portfolio $j, R_{f}=$ the risk free rate of return that is considered as a constant reference point, $E\left(R_{M}\right)=$ the expected return on the market portfolio, $\operatorname{sv}\left(\mathrm{R}_{\mathrm{M}}\right)=$ the semivariance of returns on the market portfolio (the semivariance includes only losses $(R M-R f<0)$ with respect to benchmark $R_{f}$ is defined by the following equation: ${ }^{s v\left(R_{M}\right)=E\left[\min \left(R_{M}-R_{f}, 0\right)^{2}\right]}$, and $\operatorname{csv}\left(R_{j}, R_{M}\right)=E\left[\left(R_{j}-R_{f}\right) \min \left(R_{M}-R_{f}, 0\right)\right]=$ the cosemivariance of returns below $R f$ on the security or portfolio $\mathrm{j}$ with the returns on the market portfolio.

The cosemivariance between the returns on $\mathrm{j}$ and $\mathrm{M}$ is different from the cosemivariance between $\mathrm{M}$ and $\mathrm{j}$. As a consequence of this fact, the cosemivariance matrix cannot be guaranteed to produce a positive semi-define matrix that can be used to provide a closed solution to the efficient set problem. A number of researcher papers deals with the Markowitz efficient frontier in the space of expected returns and semideviation. There include the work of Hogan and Warren (1972), Ang (1975), Harlow (1991), Markowitz, Todd, and Xu (1993), Grootveld and Hallerbach (1999), De Athayde (2001), Ballestero (2005), and Estrada (2007). Also, Mao (1970) conducted utility analysis that implies preference for portfolios in the expected return semideviation space. Moreover, a security adds to the portfolio's $M$ risk when $R_{j}<R_{f}$ and $R_{M}<R_{f}$, but reduces the portfolio's $M$ risk when $R_{j}>R_{f}$ and $R_{M}<R_{f}$.

The downside beta is defined from the following equation: 


$$
\beta_{j}^{D}=\frac{E\left[\left(R_{j}-R_{f}\right) \min \left(R_{M}-R_{f}, 0\right)\right]}{E\left[\min \left(R_{M}-R_{f}, 0\right)^{2}\right]}
$$

Jahankhani (1976) provided empirical tests for the expected return variance CAPM, as well as, for the expected return standard semivariance CAPM developed by Hogan and Waren (1974). Taking into account Roll (1977) one can say that he actually tested sample risk-return relations rather than the CAPM relations. His sample comprised of all securities in the 'CRSP' tape without missing data for the period July 1947, to June 1969. He utilized the methodology of Fama and Macbeth (1973) for both tests. The validity of the expected return standard semivariance CAPM is conducted with the aid of the following cross-sectional model:

$$
\overline{\mathrm{R}}_{\mathrm{pt}}=\hat{\gamma}_{\mathrm{ot}}+\hat{\gamma}_{1 \mathrm{t}} \beta_{\mathrm{pt}-1}^{\mathrm{D}}+\hat{\gamma}_{2 \mathrm{t}}\left(\beta_{\mathrm{pt}-1}^{\mathrm{D}}\right)^{2}+\hat{\gamma}_{3} \mathrm{~s}\left(\hat{\varepsilon}_{\mathrm{pt}-1}^{\mathrm{D}}\right)+\hat{\eta}_{\mathrm{pt}}
$$

where $\overline{\mathrm{R}}_{\mathrm{pt}}=$ the mean return on portfolio $\mathrm{p}$ estimated using the period $\mathrm{t}$ (for example 1951-53), $\beta_{\mathrm{pt}-1}^{\mathrm{D}}=$ the downside portfolio beta estimated for the period t-1 (for example 1949-51) using Equation (2), s $\left(\hat{\varepsilon}_{\mathrm{pt}-1}^{\mathrm{D}}\right)=$ the standard deviation of the residual of portfolio $p$ estimated using the period $t-1, \hat{\gamma}_{\text {ot }}, \hat{\gamma}_{1 \mathrm{t}}, \hat{\gamma}_{2 \mathrm{t}}, \hat{\gamma}_{3}=$ the regression coefficients, and $\hat{\eta}_{\mathrm{pt}}=$ the random disturbance term that has a zero mean value and it is independent of the other variables. Jahankhani (1976, p. 516) offers a method for estimating $\mathrm{s}\left(\hat{\varepsilon}_{\mathrm{pt}-1}^{\mathrm{D}}\right)$.

The results presented rejected the validity of each model. In each model the intercept was greater than the risk less rate of interest and the slope was less than the difference between the returns of the index and the risk-free security. Jahankhani (1976) concluded that these results may be due to errors of measurement in the risk-free rate of return.

Bawa and Lindenberg (1977) derived a CAPM employing a mean-lower partial moment framework. Lower partial moment is a risk measure that uses only returns that fall below some fixed level of returns. Harlow and Rao (1989) supported the general mean-lower partial moment CAPM. Using the second order partial moment of a given probability distribution of returns the following equilibrium pricing relation can be produced:

$$
E\left(R_{j}\right)=R_{f}+\left[E\left(R_{M}\right)-R_{f}\right] \frac{{ }^{C L P M} R_{f}\left(R_{M}, R_{j}\right)}{L^{2 P M} R_{f}\left(R_{M}\right)}
$$

where

LPMRf $=\int_{-\infty}^{+\infty} \int_{-\infty}^{R_{f}}\left(R_{M}-R_{f}\right)\left(R_{j}-R_{f}\right) f\left(R_{j}, R_{M}\right) d R_{M} d R_{j}=$ the cosemivariance below $R_{f}$ of the returns on the market portfolio with returns on security $j, f\left(R_{j}, R_{M}\right)=$ the joint probability density function of returns on security $j$ and the returns on the market portfolio, $\quad \mathrm{LPM}_{\mathrm{Rf}}=\int_{-\infty}^{\mathrm{R}_{\mathrm{f}}}\left(\mathrm{R}_{\mathrm{M}}-\mathrm{R}_{\mathrm{f}}\right)^{2} \mathrm{f}_{\mathrm{p}}\left(\mathrm{R}_{\mathrm{M}}\right) d \mathrm{R}_{\mathrm{M}}=$ the semivariance of returns below $R_{f}$ on the market portfolio $f_{p}\left(R_{M}\right)=$ the probability density function of returns for the market portfolio (the definition of the $2^{\text {nd }}$ - order partial moment is equivalent with that of the semivariance). Bawa and Lindenberg (1977) also offered a CAPM employing based on the nth- order partial moment of a given probability distribution of returns (Theorem 4, p. 196).

Nantell and Price (1979) provided a theoretical comparison of the expected return- variance CAPM and the expected return-semivariance CAPM and they derived the following two results: (a) The semivariance of returns of the market portfolio below $R_{f}$ is a weighted average of the values $\operatorname{csv}\left(R_{j}, R_{M}\right)$ below $R_{f}$ for all the securities in the market portfolio, where the weights are the proportions of funds invested in the securities (b) If the joint density function of rates of return on the market portfolio and on an individual security is bivariate normal, then the security expected return given by the expected return-variance CAPM is equal to that given by the expected return-semivariance CAPM. If the return distributions are normal, then $\operatorname{csv}\left(R_{j}, R_{M}\right)=\operatorname{cov}\left(R_{j}, R_{M}\right) / 2$ and $\operatorname{sv}\left(R_{M}\right)=\sigma^{2}\left(R_{M}\right) / 2$. In this case, the traditional security beta and the downside security beta are identical In contrast, for a skewed distribution the traditional security beta and the downside security beta diverge.

Nantell, Price and Price (1982) examined empirically the expected return-variance CAPM and the expected return-second order partial moment CAPM (see Equation (4) above). They argued that if the joint density 
function of rates of return on the market portfolio and on an individual security is bivariate lognormal the two models can produce different theoretical results. More specifically, they reported that (i) for securities with low systematic risk holds $\beta_{j}<\frac{\mathrm{CLPM}_{\mathrm{R}_{\mathrm{f}}}\left(\mathrm{R}_{\mathrm{M}}, \mathrm{R}_{\mathrm{j}}\right)}{\mathrm{LPM}_{\mathrm{R}_{\mathrm{f}}}\left(\mathrm{R}_{\mathrm{M}}\right)}=\beta_{\mathrm{j}}$, where $\beta_{\mathrm{j}}=$ the security $\mathrm{j}$ 's systematic risk included in the expected return-variance CAPM (ii) for securities with average systematic risk holds $\beta_{j}=\beta_{j}^{D}$, and (iii) for securities with high systematic risk holds $\beta_{j}>\beta_{j}^{D}$.

They initially tested whether the expected return-variance CAPM and the expected return-semivariance CAPM are empirically distinguishable. They used a time series of monthly returns for the 1926-1976 time period and they divided the whole period into 10 sub-periods. They also constructed 20 portfolios and they considered the following two cross-sectional regressions:

$$
\begin{aligned}
& \mathrm{R}_{\mathrm{pt}}=\hat{\lambda}_{\mathrm{ot}}+\hat{\lambda}_{1 \mathrm{t}} \beta_{\mathrm{pt}^{\prime}-1}+\hat{\mathrm{u}}_{\mathrm{pt}} \\
& \mathrm{R}_{\mathrm{pt}}=\hat{\gamma}_{\mathrm{ot}}+\hat{\gamma}_{1 \mathrm{t}} \beta_{\mathrm{pt}^{\prime}-1}^{\mathrm{D}}+\hat{\eta}_{\mathrm{pt}}
\end{aligned}
$$

where $\mathrm{R}_{\mathrm{pt}}=$ the monthly portfolio return (e.g. January 1935). The portfolio risk measures are computed as equal weighted averages of the individual security risk measures for period $t^{\prime}-1$ (eg 1930-34).

Then they tested hypothesis $\overline{\hat{\gamma}}_{\text {ot }}-\overline{\hat{\lambda}}_{\text {ot }}>0$. The average values of the coefficients are calculated as simple averages of the corresponding month-to-month coefficients estimated using the appropriate time periods. If this hypothesis is rejected, then the two models are empirically indistinguishable. Using the Hotelling $\mathrm{T}^{2}$ test, they concluded that $\overline{\hat{\gamma}}_{\text {ot }}>\overline{\hat{\lambda}}_{\text {ot }}$ for eight out of ten sub-periods. For the remaining two sub-periods, they concluded that the result $\overline{\hat{\gamma}}_{\text {ot }}<\overline{\hat{\lambda}}_{\text {ot }}$ is due to the existing significant negative skewness of returns.

Their hypotheses in relation to the validity of the expected return-second order partial moment CAPM can be summarised as follows: (a) The relationship between expected returns and downside betas is linear; (b) The downside beta computed is a complete measure of the risk of a security in the market portfolio. There is no relationship between expected returns and other risk factors; (c) The relationship between expected returns and downside beta is positive; (d) There are not restrictions on the risk less borrowing or lending. Taking into account the results of Roll (1977), the validity of these hypotheses is simply equivalent with the expected returnsemivariance efficiency of the market portfolio.

They tested their hypotheses by following the methodology of Fama and Macbeth (1973). The following model that generates realized security rates of return for each month $t$ was employed:

$$
\mathrm{R}_{\mathrm{pt}}=\hat{\gamma}_{\mathrm{ot}}+\hat{\gamma}_{1 \mathrm{t}} \beta_{\mathrm{pt}^{\prime}-1}^{\mathrm{D}}+\hat{\gamma}_{2 \mathrm{t}}\left(\beta_{\mathrm{pt}^{\prime}-1}^{\mathrm{D}}\right)^{2}+\hat{\gamma}_{3 \mathrm{t}} \mathrm{s}\left(\hat{\varepsilon}_{\mathrm{pt}}^{\mathrm{D}}-1\right)+\hat{\eta}_{\mathrm{pt}}
$$

where $\mathrm{R}_{\mathrm{pt}}=$ the monthly portfolio return (eg January 1935), and $\beta_{\mathrm{pt}^{\prime}-1}^{\mathrm{D}}=$ the portfolio downside beta computed as an equal weighted average of the individual security downside betas for period $t^{\prime}-1$ (e.g. 1930-34). Unlike Jahankhani (1976), they estimated the coefficients of Equation (6) every month and then they computed and used the monthly average coefficient values.

The term $\left(\beta_{\mathrm{pt}^{\prime}-1}^{\mathrm{D}}\right)^{2}$ had been added to test the linearity between returns and downside risk. The term $\mathrm{s}\left(\hat{\varepsilon}_{\mathrm{pt}}^{\mathrm{D}-1}\right)$ helped to test the residual risk hypothesis. The downside portfolio unsystematic risk is computed as an equal-weighted average of the individual downside unsystematic risk of the securities comprising the portfolio. They, also, used the following mean-variance model:

$$
\mathrm{R}_{\mathrm{pt}}=\hat{\mathrm{v}}_{\mathrm{ot}}+\hat{\mathrm{v}}_{1 \mathrm{t}} \beta_{\mathrm{pt} \mathrm{t}^{-1}}+\hat{\mathrm{v}}_{2 \mathrm{t}}\left(\beta_{\mathrm{pt}^{\prime}-1}\right)^{2}+\hat{\gamma}_{3} \mathrm{~s}\left(\hat{\varepsilon}_{\mathrm{pt} \mathrm{t}^{\prime}-1}\right)+\hat{\mathrm{u}}_{\mathrm{pt}}
$$

where $\beta_{\mathrm{pt}^{\prime}-1}=$ the systematic risk of a portfolio $\mathrm{p}$ for period $\mathrm{t}^{\prime}-1$.

Further their evidence revealed the following: (a) The linearity hypothesis between expected returns and downside beta cannot be rejected; (b) The residual hypothesis cannot be rejected; (c) There is a positive relationship between expected returns and downside beta. (d) The relationship between expected returns and downside beta is not exact. It holds $\overline{\hat{\gamma}}_{\mathrm{ot}}>\mathrm{R}_{\mathrm{f}}$ and $\overline{\hat{\gamma}}_{1 \mathrm{t}}<\mathrm{R}_{\mathrm{M}}-\mathrm{R}_{\mathrm{f}}$. Post and Van Vliet (2005) considered a long sample period (1926-2002) and used unconditional MV and MS tests as well as conditional tests that account for the economic state-of-the-world and concluded that the MS CAPM provides a better explanation of the 
cross-section of US stock returns than the MV CAPM. Taking into account the limitations of the downside beta as defined by Equation (2), Estrada (2002) proposed the following definition of the downside beta:

$$
\beta_{j}^{*}{ }_{j}=\frac{\operatorname{csv} *\left(R_{j}, R_{M}\right)}{\operatorname{sv} *\left(R_{M}\right)}=\frac{E\left[\min \left(R_{j}-\mu_{j}, 0\right) \min \left(R_{M}-\mu_{M}, 0\right)\right]}{E\left[\min \left(R_{M}-\mu_{M}, 0\right)^{2}\right]}
$$

where $\mu_{j}=$ the mean of security or portfolio $\mathrm{j}$ and $\mu_{\mathrm{M}}=$ the mean of the market portfolio.

In view of the above definition of cosemivariance three points can be emphasized. First, the cosemivariance between the returns on $\mathrm{j}$ and $\mathrm{M}$ is equal to the cosemivariance between $\mathrm{M}$ and $\mathrm{j}$. Second, since we consider only returns where $R_{j}<\mu_{j}$ and $R_{M}<\mu_{M}$, a security adds only to the portfolio's $M$ risk. And third, the cosemivariance matrix is symmetric. Then, Estrada (2002) expressed the D-CAPM as follows:

$$
E\left(R_{j}\right)=R_{f}+\left[E\left(R_{M}\right)-R_{f}\right] \beta_{j}^{*} D
$$

The expected return-semivariance CAPM is different from expected return-risk models that use skewness and kurtosis (Kraus and Litzenberger, 1976; Friend and Westerfield, 1980; Diacogiannis, 1994; Ditmar, 2002). Estrada (2002) also compared empirically the expected return-variance CAPM and the expected return-semivariance CAPM using the monthly returns from 27 capital indices of emerging markets for varied sample periods and the corresponding returns of the world market. Here, sample risk-return relations are tested rather than the CAPM relations (Roll, 1977).

For each index he estimated four risk measures, these being the standard deviation of returns, the traditional beta, the semivariance and the downside beta. The evidence produced from regressing the mean returns of the indices on each risk measure, reveal four significant and positive relations and that the downside risk provides a higher coefficient of determination as compared with each of the remaining risk measures. Then he utilized two cross-sectional regressions having as dependent variable the indices' mean returns and as independent variables the pairs (standard-deviation, semivariance) and (beta, downside beta), respectively. The results indicated that first cross-section multi-regression produces insignificant results while for the second regression only the downside beta shows to affect significantly mean returns. Finally, a comparison between the mean returns produced by the expected return-variance CAPM and those derived using the expected return-semivariance CAPM shows that the latter is greater than the former for each market. Estrada (2001) provides an argument that the semi-deviation is more useful than the standard deviation when the security returns obey skewed distributions and just as useful when the security distributions are symmetric.

Finally, Post and Van Vliet (2005) used monthly US security returns, the sample period from January 1926 to December 2002 and concluded that the expected return-semivariance CAPM outperforms the expected return-variance CAPM in explaining cross-sectional mean returns. Additionally they inferred that the explanatory power of the conditional downside beta remains after controlling for size and momentum effects.

\section{Research Data}

The present study employs two time-series samples of weekly security returns. We confined our attention to continuously listed firms on the London Stock Exchange (LSE) and Paris Stock Exchange (PASE) during two periods, January 1997 to December 2002 and January 1999 to December 2004, respectively. This sample criterion probably introduces a survival bias. We believe that this survival bias is unlikely to produce a systematic bias on the results. With this objective in mind 260 securities were selected from the LSE for each sample period. Also, 161 securities were selected from the PASE for the sample period 1997 to 2002 and 207 for the period 1999 to 2004. For risk analysis it is particular important to analyze periods during which risks are high. Having this in mind, the sample period of this study is selected to include the bear markets of 2000s.

Before proceeding further, it would be useful to pause briefly and discuss the technique of security return calculation. For each security in the sample weekly prices were extracted and the return on a security $i$ at the end of period $t$ is calculated by: $R_{i t}=\ln \left(P_{i t}+d_{t}\right)-\ln \left(P_{i t-1}\right)$, where $\ln =$ the natural logarithm operator, $P_{i t}=$ the last traded price for security $\mathrm{i}$ in period $\mathrm{t}$ (price were adjusted for capital changes), $\mathrm{P}_{\mathrm{it}-1}=$ the last traded price for security $i$ in period $t-1$ adjusted to the same base, and $d_{i t}=$ the dividend for security $i$ declared $x d$ during the period t. 
The present study uses the FTSE-100 to calculate UK betas and the CAC-40 for the calculation of the betas of the firms listed in the PASE.

The study considers four risk measures, two related to the expected return variance framework (standard-deviation and beta) and two related to the expected return standard semivariance analysis (semi-deviation and downside beta). It examines whether each risk measure related to the expected return standard semivariance analysis provide more explanatory power of mean returns from the corresponding risk measure associated to the expected return variance framework. The empirical results are using both individual securities and portfolios.

The first period from January 1997 to December 2002 was divided into two sub-periods one from January 1997 to December 1998 and the other from January 1999 to December 2002. The first sub-period is used to form portfolios and the second is employed to test our hypotheses (he securities are ranked into portfolios by observed betas). Similarly the second period from January 1999 to December 2004 produced two sub-periods one from January 1999 to December 2000 and the other from January 2001 to December 2004. Again the first sub-period provides data for portfolio formation and the second is utilized to test our hypotheses.

\section{Empirical Results and Implications}

The following cross-sectional linear simple regression was used to relate security mean returns with each risk measure:

$$
\mathbf{M R}_{\mathbf{i}}=\gamma_{\mathbf{0}}+\gamma_{\mathbf{1}} \mathbf{R} \mathbf{V}_{\mathbf{i}}+\mathbf{u}_{\mathbf{i}}
$$

where $\mathbf{M R}_{\mathbf{i}}=$ the mean return of security $\mathrm{i}, \mathbf{R} \mathbf{V}_{\mathbf{i}}=$ the risk variable for security $\mathrm{I}$ (the four risk variables considered are standard-deviation, semi-deviation, beta, and downside beta), $\gamma_{0}, \gamma_{1}=$ the regression coefficients, and $\mathbf{u}_{\mathbf{i}}=$ the error term. As usual, the error term is assumed to have zero mean and constant variance and to be independent from the independent variable.

Table 1 presents the results of the four cross-sectional simple regressions (II.1) for Great Britain using individual securities and two sub-periods one from 1999 to 2002 and the other from 2001 to 2004 . From Table 1 it can be seen that all four risk variables provide significant slope coefficients. For both periods, the semi-deviation (downside beta) explains more of the variability in mean returns than the standard deviation (beta).

The same analysis were repeated for 26 and 52 portfolios respectively (see Tables 2 and 3). The results of Table 2 indicate again that the coefficients of all four risk measures are statistically significant. For the sub- period from 1999 to 2002 the semi-deviation (downside beta) is performing slightly better (worst) than the standard deviation (beta) in terms of explanatory power. However, for the sub-period from 2001 to 2004 the standard deviation (beta) is slightly better in terms of explanatory power than the semi-deviation (downside beta). The high values of the adjusted $\mathrm{R}^{2}$ may be due to the small number of observations. Then, 52 portfolios are considered. The results of Table 3 are using 52 portfolios and are similar with those included in Table 2.

The present work also employs the following bi-variate cross-sectional regression:

$$
\mathbf{M R}_{\mathrm{i}}=\gamma_{0}+\gamma_{1} \mathbf{R V _ { 1 i }}+\gamma_{2} \mathbf{R V}_{2 \mathrm{i}}+\mathbf{u}_{\mathrm{i}}
$$

where $\mathbf{M R}_{\mathbf{i}}=$ the mean return of security i, $\mathbf{R} \mathbf{V}_{\mathbf{i} 1}, \mathbf{R V}_{\mathbf{i} 2}=$ the first and second risk variable for security i, $\gamma_{\mathbf{0}}, \gamma_{1}$, $\gamma_{2}=$ the regression coefficients, and $\mathbf{u}_{\mathbf{i}}=$ the error term. Here is also assumed that the error term has zero mean and constant variance and is independent from the independent variables.

The results of the cross-sectional bi-variate regression (II.2) for Great Britain using individual securities and two subperiods are included in Table 4. For the sub-period 1999-2002 both the standard deviation and semi-deviation are significant while for the sub-period 2001- 2004 only the semi-deviation is significant. When beta and downside beta are jointly regressed, only the downside beta is significant for the sub-period 1999-2002 and both betas are significant for the subperiod 2001-2004. This result shows that for the sub-period 1999-2002 the traditional beta does not contain information which is not included in the downside beta. Also, it reveals for individual securities the superiority of the downside risk measures against the risk measures related to the expected return variance framework.

From Table 5, one can see that for the sub-period 1999-2002 both the standard deviation and semi-deviation are insignificant while for the sub-period 2001- 2004 they are significant. The former result is likely to be attributable to the high correlation between the standard deviation and the semi-deviation (0.99). When beta and downside beta are jointly regressed, neither the beta nor the downside beta is significant for both sub-periods. Again it is observed a high correlation between these two explanatory variables (0.98). 
The results of Table 6 reveal that both the standard deviation and semi-deviation are significant for both sub-periods. When beta and downside beta are jointly considered, neither the beta nor the downside beta is significant for both sub-periods.

Taking together the results from Great Britain one can see that each of the four risk variables affects significantly security or portfolio mean returns. For individual securities, the downside risk measures are the best performing variables in terms of explanatory power. For portfolios the results are mixed. In some cases the semi-deviation is a slightly better performer than the standard deviation and in other cases it is not. However, the beta is a slightly better performer than the downside beta.

Furthermore, when the standard deviation and the semi-deviation are jointly considered in most cases affect significantly mean returns. For individual securities, when beta and the downside beta are jointly employed only the downside beta affects significantly mean returns. For portfolios, when these two variables are jointly considered, neither beta nor the downside beta is significant. Therefore, for individual securities the downside risk measures are better for explaining mean returns than the standard deviation and beta. For portfolios one cannot conclude a superiority of the downside beta against the beta.

The results of the cross-sectional regression (II.1) for France utilizing individual securities are included in Table 7. The results reveal that each of the four risk measures significantly affects mean returns. Also, for each period, the semi-deviation (downside beta) is the best-performing variable in terms of explanation of the variability in mean returns than the standard deviation (beta). These findings are in line with those presented in Table 1.

The results of Table 8 are produced with the aid of 20 portfolios. For each sub-period the standard deviation provides a slightly better explanation of the variability in mean returns than the semi-deviation. However, the downside beta explains more of the variability in mean returns than the beta.

The results of Table 9 are relying on 32 and 41 portfolios respectively and they are similar to those shown in Table 8.

Table 10 contains the results of the cross-sectional bi-variate regression (II.2) for France employing individual securities. For each sub-period the standard deviation provides an insignificant coefficient. This is also apparent after comparing for each sub-period the explanatory power provided by the cross-sectional linear simple regression (II.1) (see Table 7) with the explanatory power shown in Table 10. The inclusion of the standard deviation into the simple regression that has the semi-deviation as explanatory variable left almost unchanged the value of the adjusted $\mathrm{R}^{2}$. Similarly, for the sub-period 2001-04 beta gives an insignificant coefficient. Again the consideration of beta as an additional variable into the simple regression that has the downside beta as independent variable left unchanged the value of the adjusted $\mathrm{R}^{2}$.

For the sub-period 1999-02 both betas produce significant coefficients. However, the downside beta provides in absolute terms higher t-statistics as compare with that of beta.

From Table 11 we observe that neither the standard deviation nor the semi-deviation provide significant coefficients. However, as we see from Table 11, for each sub-period, the bi-variate regression produces a high $\mathrm{R}^{2}$. This is likely to be attributable to the high correlation between the standard deviation and the semi-deviation (0.997 for the sub-period 1999-02 and 0.996 for the sub-period 2001-04). Similar results apply for the bi-variate regressions using as explanatory variables beta and downside beta. Again high correlations between beta and downside beta are observed.

From Table 12 one can see that in each sub-period the standard deviation and the semi-deviation are related with insignificant coefficients. In each case the correlation between the standard deviation and the semi-deviation is very high (0.995 for the sub-period 1999-02 and 0.9958 for the sub-period 2001-04). For the sub-period 1999-02 both the beta and the downside beta are insignificant. However, for the sub-period 2001-04 only the downside beta gives a significant coefficient.

Summarizing the results from France one can observe that each of the four risk variables influences significantly security or portfolio mean returns. The downside risk measures are equivalent or better than the traditional risk measures in terms of explanatory power. For individual securities, when the standard deviation and the semi-deviation are jointly considered only the semi-deviation influences significantly mean returns. For portfolios both the standard deviation and the semi-deviation provide insignificant coefficients. Moreover for portfolios, when beta and the downside beta are jointly employed the downside beta is equivalent or better than the traditional beta in terms of explanatory power. Finally, collecting together the results from both markets it can be seen that in most cases the semi-deviation is a better performing variable than the standard deviation in 
terms of explanatory power. Also a similar conclusion is derived for the down-side beta as compared with the traditional beta.

\section{Research Results Possible Explanation}

In this part of the article we will offer a possible explanation for the negative coefficients observed utilizing the cross-sectional simple regressions. Firstly, introduced is a new risk-return relation that holds for normal distributions of security returns and market indices lying inside the semi-deviation-expected return efficient frontier.

Suppose that the distributions of security returns are normal. If the market index, call it M1, is an inefficient portfolio in the space of mean return - standard deviation, then Diacogiannis (1999) provided the following return generating model:

$$
R_{M 1}=R_{\mathrm{M}}+U_{M 1}
$$

where $M$ is a frontier portfolio with $\mathrm{E}\left(\mathrm{R}_{\mathrm{M}}\right)=\mathrm{E}\left(\mathrm{R}_{\mathrm{M} 1}\right)$ and $\sigma\left(R_{M}\right)>\sigma\left(R_{\mathrm{M} 1}\right)$, and $\mathrm{U}_{\mathrm{M} 1}=$ a residual return with $\mathrm{E}\left(\mathrm{U}_{\mathrm{M} 1}\right)=0$ and $\operatorname{Cov}\left(\mathrm{R}_{\mathrm{M}}, \mathrm{U}_{\mathrm{M} 1}\right)=0$ (Diacogiannis (1999). We also assume that portfolio $\mathrm{M} 1$ has an expected return greater than the expected return of the GMVP. The GMVP is excluded because a zero beta portfolio does not exist there (Roll, 1977).

The portfolio frontier is the set of minimum variance portfolios of risky assets for all expected Returns (Roll, 1977). The frontier portfolio with the least variance is called the global minimum variance portfolio (GMVP). Then he introduced the following risk-return model:

$$
E\left(R_{j}\right)=E\left(R_{z M 1}\right)+\left[E\left(R_{M 1}\right)-E\left(R_{z M 1}\right)\right] \frac{\operatorname{Cov}\left(R_{j}, R_{M 1}\right)}{\sigma^{2}\left(R_{M}\right)}-\left[E\left(R_{M 1}\right)-R_{z M 1}\right] \frac{\operatorname{Cov}\left(R_{j}, U_{M 1}\right)}{\sigma^{2}\left(R_{M}\right)}
$$

where $E\left(R_{j}\right)=$ the expected return of security $\mathrm{j}, \mathrm{E}\left(\mathrm{R}_{\mathrm{zM} 1}\right)=$ the expected return of the portfolio whose returns are uncorrelated with those of $M, \operatorname{Cov}\left(R_{j}, R_{M 1}\right)=$ the covariance between the returns of security $\mathrm{j}$ and the returns of the inefficient portfolio $\mathrm{M}$, and $\operatorname{Cov}\left(R_{j}, U_{M 1}\right)=$ the covariance between the returns of security $\mathrm{j}$ and the residual return. This model is based on two assumptions (i) The variance-covariance matrix of securities is a non-singular positive definite matrix, and (ii) There are at least two securities with different expected returns.

Equation (12) reveals that the expected return on a security can be written as a linear function of its risk in an inefficient portfolio and an additional risk of the security associated with moving inside the efficient frontier.

When the security returns are normally distributed, then $\operatorname{Cov}\left(R_{j}, R_{M 1}\right)=2 \operatorname{csv}\left(R_{j}, R_{M 1}\right)$ and $\sigma^{2}\left(\mathrm{R}_{\mathrm{M}}\right)=2 \operatorname{sv}\left(\mathrm{R}_{\mathrm{M}}\right)$. Thus Equation (11) becomes:

$$
E\left(R_{j}\right)=E\left(R_{z M 1}\right)+\left[E\left(R_{M 1}\right)-E\left(R_{z M 1}\right)\right] \frac{\operatorname{csv}\left(R_{j}, R_{M 1}\right)}{s v\left(R_{M}\right)}-\left[E\left(R_{M 1}\right)-R_{z M 1}\right] \frac{\operatorname{csv}\left(R_{j}, U_{M 1}\right)}{s v\left(R_{M}\right)}
$$

Equation (13) can be also written as

$$
E\left(R_{j}\right)=E\left(R_{z M 1}\right)+\left[E\left(R_{M 1}\right)-E\left(R_{z M 1}\right)\right] \frac{s v\left(R_{M 1}\right)}{s v\left(R_{M}\right)} \beta_{j M 1}^{* D}-\left[E\left(R_{M 1}\right)-R_{z M 1}\right] \frac{s v\left(U_{M 1}\right)}{s v\left(R_{M}\right)} \beta_{j U_{M 1}}^{* D}
$$

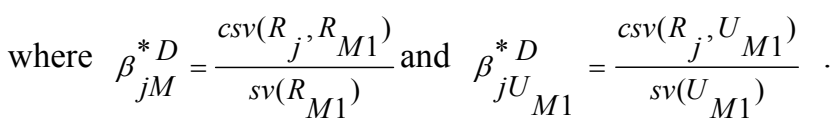

If the distributions of security returns are normal, in our work we estimated a single linear regression equation having as independent variable the traditional beta (or the downside beta) whereas the true theoretical relation is given by Equation (14). In this case a relevant variable that influence security (portfolio) mean returns was left out. This variable is negatively correlated with security mean returns and the estimates of the slope coefficients for the single linear regressions can be biased.

On the other hand, if the probability distributions of security returns are skewed, then it is better to take into consideration to the analysis skewness and conduct portfolio analysis in three moments rather than using the semivariance. In this case if we use single linear regressions then we also have misperceived models since an 
important explanatory variable is left out (Kraus \& Lintenberger, 1976; Friend and Westerfield, 1980; Diacogiannis, 1994; Harvey and Siddique, 2000).

Hence in summary, if the security returns are normally distributed, then the return-semivariance CAPM and the return-variance CAPM are identical. If the probability distributions of security returns are skewed it may be better to utilize a three parameter asset pricing that takes into consideration the skewness of return distributions.

\section{Conclusions}

The present work uses returns of securities traded on the London Stock Exchange and Paris Stock Exchange and investigates empirically the relationship between risk and return in a downside risk framework and in a regular risk framework. The four risk variables considered are two associated with the expected return variance framework (standard-deviation and beta) and two related with the expected return standard semivariance analysis (semi-deviation and downside beta).

Summarizing the results from Great Britain it can be seen that for individual securities the downside risk measures are better in explaining mean returns than the standard deviation and beta. For portfolios one cannot conclude a superiority of the downside beta against the beta.

Collecting the results from France it can be observed that for individual securities only the semi-deviation influences significantly mean returns when the standard deviation and the semi-deviation are jointly used. For portfolios both the standard deviation and the semi-deviation provide insignificant coefficients. Furthermore, for portfolios the downside beta is equivalent or better than the traditional beta in terms of explanatory power when beta and the downside beta are jointly considered.

If the distribution of security returns are normal and the market index lies inside the semi-deviation-expected return efficient frontier, then the expected return on any security can be expressed as an exact linear function of two variables, its risk in that portfolio and an additional risk associated with moving inside the efficient portfolio set. Thus, when dealing with portfolios that are lying inside the boundary portfolio set both variables that influence cross-sectionally security expected returns should be taken into consideration. The existence of such a new relation between risk and return can be considered as a possible explanation of the results offered in this study.

Finally, for normally distributed security returns, the SV-CAPM is identical with the MV-CAPM. On the other hand, if the probability distributions of security returns are skewed it may be better to consider skewness to the analysis and use a three parameter asset pricing rather than employ the SV-CAPM.

Acknowledgements: We would like to thank Professor G. Hardouvelis, Professor A. Antzoulatos and Associate Professor M. Tsiritakis from the University of Piraeus for their constructive comments.

\section{References}

Ang J. (1975). A Note on the E,S,L Portfolio Selection Model. Journal of Financial \& Quantitative Analysis, 10, 849-857.

Ballestero E. (2005). Mean-Semivariance Efficient Frontier: A Downside Risk Model for Portfolio Selection. Applied Mathematical Finance, 12, 1-15.

Aparicio F. \& Estrada J. (2001). Empirical Distributions of Stock Returns: European Securities Markets, 1990-95. European Journal of Finance, Vol. 7, 1-21.

Bakaert G. (1995). Market Integration and Investment Barriers in Emerging Equity Markets. World Bank Economic Review, Vol. 9, 75-107.

Bawa V. (1978). Safety First, Stochastic Dominance, and Optimal Portfolio Choice. Journal of Financial \& Quantitative Analysis, Vol. 13, No 2, 255-271.

Bawa V. \& Lindrenberg E. (1977). Capital Market Equilibrium in a Mean-Lower Partial Moment Framework. Journal of Financial Economics, Vol. 5, 189-200.

Blume M. (1971). On the Assessment of Risk. Journal of Finance, Vol. 26, 1-10.

Blume M.E. (1970). Portfolio Theory: A Step towards Its Practical Application. Journal of Business, Vol. 43, 34-105.

De Athayde, G. (2001). Building a Mean-Downside Risk Portfolio Frontier. In F. Sortino and S. Satchell (Eds), Managing Downside Risk in Financial Markets, Batterworth-Heinemann Finance. 
Diacogiannis G. (1994). Three Parameter Asset Pricing, Managerial and Decision Economics. (January), Vol. 15, 149-158.

Diacogiannis G. (1999). A Three-dimensional Relationship based upon the Inefficiency of a Portfolio: Derivation and Implications. The European Journal of Finance, Vol. 5, 225-235.

Dittmar R. F. (2002). Nonlinear Pricing Kernels, Kurtosis Preference and Evidence from the Cross Section of Equity Returns. Journal of Finance, Vol. 57, 369-403.

Estrada J. (2000). The Cost of Equity in Emerging Markets: A Downside Risk Approach. Emerging Markets Quarterly, 19-30.

Estrada J. (2001). The Cost of Equity in Emerging Markets: A Downside Risk Approach (II). Emerging Markets Quarterly, 63-72.

Estrada J. (2002a). The Cost of Equity Internet Stocks: A Downside Risk Approach. Working Paper, IESE Business School.

Estrada J. (2002b). Systematic Risk in Emerging markets: The D-CAPM. Emerging Markets Review, Vol. 4, $365-379$.

Estrada J. (2002c). Systematic Risk in Emerging Markets: The D-CAPM. Emerging Markets Review, Vol. 3, 365-379.

Estrada J. (2007). Mean-Semivariance Optimization: A Heuristic Approach. Working Paper, IESE Business School, Spain.

Fama E.F. \& MacBeth J.D. (1973). Risk, Return and Equilibrium: Empirical Tests. Journal of Political Economy, 607-636.

Fishburn P. (1977). Mean-Risk Analysis with Risk Associated with Below-Target Returns. The American Economic Review, Vol. 67, No 2, 16-126.

Frank M. \& Wolfe P. (1956). An Algorithm for Quadric Programming. Naval Research Logistics Quarterly, Vol. 3, 95-110.

Friend, I. \& Westrerfield R. (1980). Co-skewness and Capital Asset Pricing. Journal of Finance, Vol. 35, 897-013.

Grootveld H. and Hallerbach W. (1999). Variance vs Downside Risk: Is There Reality that Much Difference. European Journal of Operational Research, Vol. 114, 304-319.

Harlow V. (1991). Asset Allocation in a Downside Risk Framework. Financial Analyst Journal, September/October, 28-40.

Harlow W.V. \& Rao K.S. (1989). Asset Pricing in a Generalized Mean-Lower Partial Moment Framework: Theory \& Evidence. Journal of Financial \& Quantitative Analysis, Vol. 24, 285-311.

Harvey, C. (2000). Drivers of Expected Returns in International Markets. Emerging Markets Quarterly, Fall, 32-48.

Harvey, C. R. and A. Siddique, (2000). Conditional skewness in asset pricing tests. Journal of Finance, Vol. 55, 1263-1295.

Hogan W. \& Warren J. (1972). Computation of the Efficient Boundary in the

E-S Portfolio Selection Model., Journal of Financial \& Quantitative Analysis, Vol. 7, No 4, 1881-1896.

Hogan W. \& Warren J. (1974). Towards the Development of an Equilibrium

Capita I-Market Model Based on Semivariance. Journal of Financial \&

Quantitative Analysis, Vol. 9, 1-11.

Jahankhani Ali (1976). E-V and E-S Capital Asset Pricing Models: Some Empirical Tests. Journal of Financial \& Quantitative Analysis, Vol. 11, IMo4, 513-528.

Kraus A. \& Lintenberger R. (1976). Skewness Preference and the Valuation of Risky Assets. Journal of Finance, Vol. 31, 1085-1100.

Lintner J. (1972). Equilibrium in a Random Walk and LognormaJ Securities Market. Discussion Paper No 235, Harvard University Institute of Economic Research.

Lintner J. (1965). Security Prices, Prices \& Maximal Gains from Diversification. Journal of Finance, Vol. 20, 349-360. 
Mao J. (1970). Models of Capital Budgeting, E-V Vs E-S. Journal of Financial \& Quantitative Analysis, Vol. 4, No 5, 657-675.

Markowitz H. (1959). Portfolio Selection. New York: John Willey \& Sons Inc.

Markowitz H. (1991). Foundations of Portfolio Theory. Journal of Finance, Vol. 46, 469-477.

Markowitz H., Todd P. and Xu, G. (1993). Computation of Mean-Semivariance Efficient Sets by the Critical Line Algorithm. Annuals of Operations Research, Vol. 45, 307-317.

Miller M.H. \& Scholes M.S. (1972). Rates of Returns in Relation to Risk: A Re-examination of Recent Findings. In Michael Jensen (Eds), Studies in the Theory of Capital Markets, New York: Praeger.

Nantell T. \& Price B. (1979). An Analytical Comparison of Variance and Semivariance Capital Market Theories. Journal of Financial \& Quantitative Analysis, Vol. 14, No 2, 221-242.

Nantell T.J., Price K. and Price B. (1982). Mean-Lower Partial Moment Asset Pricing Model: Some Empirical Evidence. Journal of Financial \& Quantitative Analysis, Vol. 17, No 5, 763-782.

Post T. and Van Viliet P. (2005). Empirical tests of the mean-semivariance CAPM. [Online] Available: http://papers.ssrn.com/sol3/papers.cfm?abstract_id=557220.

Post, T. and P. Van Vliet. (2004). Downside Risk and Asset Pricing. Working paper, Erasmus University, Rotterdam.

Roll, R. (1977). A Critique of the Asset Pricing Theory's Tests, Part I: on Past and Potential Testability of the Theory. Journal of Financial Economics, Vol. 4, 129-176.Sharpe W.F. (1964). Capital Asset Prices: A Theory of Equilibrium under conditions of Risk. Journal of Finance, Vol. 19, 425-442.

Table 1. Estimating the cross-sectional simple linear regression model $\mathbf{M R}_{\mathbf{i}}=\gamma_{\mathbf{o}}+\gamma_{1} \mathbf{R} \mathbf{V}_{\mathbf{i}}+\mathbf{u}_{\mathbf{i}}$ for individual securities (Great Britain)

\begin{tabular}{|c|c|c|c|c|c|c|}
\hline \multicolumn{5}{|c|}{ Sub-period 1999-2002 } & \multicolumn{3}{c|}{ Sub-period 2001-2004 } \\
\hline $\begin{array}{c}\text { Risk measure } \\
\left(\mathbf{R V}_{\mathbf{j}}\right)^{*}\end{array}$ & $\gamma_{\mathbf{0}}$ & $\gamma_{\mathbf{1}}$ & Adj-R & $\gamma_{\mathbf{0}}$ & $\gamma_{\mathbf{1}}$ & Adj-R $^{\mathbf{2}}$ \\
\hline$\sigma$ & 0.0042 & $-0,0903$ & 0.311 & 0.0045 & -0.0914 & 0.309 \\
& $(9.06)$ & $(-10.86)$ & & $(10.68)^{* *}$ & $(-10.82)$ & \\
\hline$\Sigma$ & 0.0044 & -0.1332 & 0.387 & 0.0042 & -0.1191 & 0.325 \\
& $(10.67)$ & $(-12.83)$ & & $(10.97)$ & $(-11.22)$ & \\
\hline$\beta$ & 0.0018 & -0.0036 & 0.229 & 0.0041 & -0.0049 & 0.442 \\
& $(5.79)$ & $(-8.85)$ & & $(14.04)$ & $(-14.96)$ & \\
\hline$\beta^{\mathrm{D}}$ & 0.0033 & -0.0038 & 0.275 & 0.0052 & -0.0046 & 0.454 \\
& $(7.96)$ & $(-9.98)$ & & $(14.33)$ & $(-15.23)$ & \\
\hline
\end{tabular}

* $\sigma=$ the standard deviation of returns, $\Sigma=$ the semideviation of returns, $\beta=$ the beta coefficient

(with respect to FTSE-100), and $\beta^{\mathrm{D}}=$ the downside beta with respect to FTSE-100).

$* * \mathrm{t}$ statistics are included in parentheses. Critical value for a two-sided test at $1 \%$ significant level: 2.58

Table 2. Estimating the cross-sectional simple linear regression model $\operatorname{MRp}=\gamma_{0}+\gamma_{1} \mathbf{R V} V_{p}+u_{p}$ for 26 portfolios (Great Britain)

\begin{tabular}{|c|c|c|c|c|c|c|}
\hline \multicolumn{5}{|c|}{ Sub-period $1999-2002$} & \multicolumn{3}{|c|}{ Sub-period 2001-2004 } \\
\hline $\begin{array}{c}\text { Risk measure } \\
\left(\mathrm{RV}_{\mathrm{j}}\right)^{*}\end{array}$ & $\gamma_{\mathrm{o}}$ & $\gamma_{1}$ & Adj-R & $\gamma_{\mathrm{o}}$ & $\gamma_{1}$ & Adj-R $^{2}$ \\
\hline$\sigma$ & 0.0037 & -0.1535 & 0.489 & $\begin{array}{c}0.0055 \\
(9.02)^{* *}\end{array}$ & $\begin{array}{c}-0.1967 \\
(-8.93)\end{array}$ & 0.759 \\
\hline$\Sigma$ & $(4.21)$ & $(-4.99)$ & & 0.0058 & -0.2784 & 0.716 \\
& 0.0038 & -0.2125 & 0.516 & $(8.13)$ & $(-8.01)$ & \\
\hline$\beta$ & $(4.46)$ & $(-5.26)$ & & 0.0047 & -0.00562 & 0.822 \\
& 0.0024 & -0.00441 & 0.525 & $(10.76)$ & $(-10.80)$ & \\
\hline$\beta^{\mathrm{D}}$ & $(4.04)$ & $(-5.36)$ & & 0.0053 & -0.0054 & 0.798 \\
& 0.00304 & -0.00438 & 0.491 & $(10.05)$ & $(-9.99)$ & \\
\hline
\end{tabular}

$* \sigma=$ the standard deviation of returns, $\Sigma=$ the semideviation of returns, $\beta=$ the beta coefficient, and $\beta^{\mathrm{D}}=$ the downside beta.

** $\mathrm{t}$ statistics are included in parentheses. Critical value for a two-sided test at $1 \%$

significance level: 2.58 
Table 3. Estimating the cross-sectional simple linear regression model $\mathbf{M R p}=\gamma_{0}+\gamma_{1} \mathbf{R} V_{p}+u_{p}$ for 52 portfolios (Great Britain)

\begin{tabular}{|c|c|c|c|c|c|c|}
\hline \multicolumn{5}{|c|}{ Sub-period 1999-2002 } & \multicolumn{3}{|c|}{ Sub-period 2001-2004 } \\
\hline $\begin{array}{c}\text { Risk measure } \\
\left(\mathrm{RV}_{\mathrm{j}}\right)^{*}\end{array}$ & $\gamma_{\mathrm{o}}$ & $\gamma_{1}$ & Adj-R & $\gamma_{\mathrm{o}}$ & $\gamma_{1}$ & Adj-R $^{2}$ \\
\hline$\sigma$ & 0.0030 & -0.1130 & 0.336 & 0.0051 & -0.1640 & 0.582 \\
& $(4.27)$ & $(-5.18)$ & & $(8.59)^{* *}$ & $(-8.49)$ & \\
\hline$\Sigma$ & 0.0032 & -0.5667 & 0.378 & 0.0052 & -0.2202 & 0.539 \\
& $(4.71)$ & $(-5.26)$ & & $(7.90)$ & $(-7.79)$ & \\
\hline$\beta$ & 0.0021 & -0.00401 & 0.442 & 0.0044 & -0.00525 & 0.675 \\
& $(4.71)$ & $(-6.43)$ & & $(10.26)$ & $(-10.34)$ & \\
\hline$\beta^{\mathrm{D}}$ & 0.0028 & -0.0039 & 0.411 & 0.0051 & -0.00512 & 0.664 \\
& $(4.80)$ & $(-6.05)$ & & $(10.13)$ & $(-10.09)$ & \\
\hline
\end{tabular}

$* \sigma=$ the standard deviation of returns, $\Sigma=$ the semideviation of returns, $\beta=$ the beta coefficient, and $\beta^{\mathrm{D}}=$ the downside beta.

** $\mathrm{t}$ statistics are included in parentheses. Critical value for a two-sided test at $1 \%$

significance level: 2.58

Table 4. Estimating the cross-sectional simple linear regression model $\mathbf{M R}_{\mathrm{i}}=\gamma_{\mathbf{0}}+\gamma_{\mathbf{1}} \mathbf{R} \mathbf{V}_{1 \mathrm{i}}+\gamma_{2} \mathbf{R} \mathbf{V}_{2 \mathrm{i}}+\mathbf{u}_{\mathrm{i}}$ for individual securities (Great Britain)

\begin{tabular}{|c|c|c|c|c|c|c|c|c|}
\hline \multicolumn{5}{|c|}{ Sub-period 1999-2002 } & \multicolumn{4}{|c|}{ Sub-period 2001-2004 } \\
\hline $\begin{array}{c}\text { Pair of Risk } \\
\text { measures } \\
\left(\mathrm{RV}_{1 \mathrm{i}} / \mathrm{RV}_{2 \mathrm{i}}\right)\end{array}$ & $\gamma_{0}$ & $\gamma_{1}$ & $\gamma_{2}$ & Adj- $R^{2}$ & $\gamma_{0}$ & $\gamma_{1}$ & $\gamma_{2}$ & $\operatorname{Adj}-R^{2}$ \\
\hline$\sigma / \Sigma$ & $\begin{array}{c}0.0032 \\
(7.79)\end{array}$ & $\begin{array}{c}0.2975 \\
(7.13)\end{array}$ & $\begin{array}{r}-0.5207 \\
(-9.44)\end{array}$ & 0.486 & $\begin{array}{l}0.0039 \\
(8.63)^{*}\end{array}$ & $\begin{array}{c}0.0811 \\
(1.29)\end{array}$ & $\begin{array}{r}-0.2215 \\
(-2.77)\end{array}$ & 0.327 \\
\hline$\beta / \beta^{\mathrm{D}}$ & $\begin{array}{c}0.0033 \\
(6.87)\end{array}$ & $\begin{array}{c}-0.0009 \\
(0.092)\end{array}$ & $\begin{array}{c}-0.0039 \\
(-4.04)\end{array}$ & 0.273 & $\begin{array}{l}0.0048 \\
(12.96)\end{array}$ & $\begin{array}{c}-0.0028 \\
(-3.56)\end{array}$ & $\begin{array}{c}-0.0021 \\
(-2.96)\end{array}$ & 0.478 \\
\hline
\end{tabular}

* $\sigma=$ the standard deviation of returns, $\Sigma=$ the semideviation of returns, $\beta=$ the beta coefficient (with respect to FTSE-100), and $\beta^{\mathrm{D}}=$ the downside beta (with respect to FTSE-'.

** t statistics are included in paretneshes. Critical value for a two-sided test at $1 \%$ significant level: 2.58

Table 5. Estimating the cross-sectional simple linear regression model $\mathbf{M R}_{\mathrm{i}}=\gamma_{\mathbf{0}}+\gamma_{1} \mathbf{R} \mathbf{V}_{1 \mathrm{i}}+\gamma_{\mathbf{1}} \mathbf{R} \mathbf{V}_{2 \mathrm{i}}+\mathbf{u}_{\mathrm{i}}$ for 26 portfolios (Great Britain)

\begin{tabular}{|c|c|c|c|c|c|c|c|c|}
\hline \multicolumn{5}{|c|}{ Period 1999-2002 } & \multicolumn{4}{|c|}{ Period 2001-2004 } \\
\hline $\begin{array}{c}\text { Pair of Risk } \\
\text { measures } \\
\left(\mathrm{RV}_{1 \mathrm{i}} / \mathrm{RV}_{2 \mathrm{i}}\right)\end{array}$ & $\gamma_{0}$ & $\gamma_{1}$ & $\gamma_{2}$ & Adj- $R^{2}$ & $\gamma_{o}$ & $\gamma_{1}$ & $\gamma_{2}$ & $\operatorname{Adj}-R^{2}$ \\
\hline$\sigma / \Sigma$ & $\begin{array}{l}0.0039 \\
(4.51) \\
\end{array}$ & $\begin{array}{l}0.2436 \\
(0.893) \\
\end{array}$ & $\begin{array}{l}-0.5392 \\
(-1.46) \\
\end{array}$ & 0.512 & $\begin{array}{c}0.0039 \\
(4.73)^{* *}\end{array}$ & $\begin{array}{r}-0.7640 \\
(-3.42) \\
\end{array}$ & $\begin{array}{l}0.8285 \\
(2.55) \\
\end{array}$ & 0.804 \\
\hline$\beta / \beta^{\mathrm{D}}$ & $\begin{array}{l}0.0023 \\
(2.54)\end{array}$ & $\begin{array}{c}-0.00465 \\
(1.30)\end{array}$ & $\begin{array}{l}0.0002 \\
(0.069)\end{array}$ & 0.505 & $\begin{array}{l}0.0047 \\
(7.87)\end{array}$ & $\begin{array}{l}-0.0054 \\
(-1.76)\end{array}$ & $\begin{array}{c}-0.00019 \\
(-0.06)\end{array}$ & 0.814 \\
\hline
\end{tabular}

$* \sigma=$ the standard deviation of returns, $\Sigma=$ the semideviation of returns, $\beta=$ the beta coefficient, and $\beta^{\mathrm{D}}=$ the downside beta.

** $\mathrm{t}$ statistics are included in parentheses. Critical value for a two-sided test at $1 \%$ significant level: 2.58

Table 6. Estimating the cross-sectional simple linear regression model $\mathbf{M R}_{\mathrm{i}}=\gamma_{0}+\gamma_{1} \mathbf{R V} \mathbf{V}_{1 \mathrm{i}}+\gamma_{1} \mathbf{R} \mathbf{V}_{2 \mathrm{i}}+\mathbf{u}_{\mathrm{i}}$ for 52 portfolios (Great Britain)

\begin{tabular}{|c|c|c|c|c|c|c|c|c|}
\hline \multicolumn{5}{|c|}{ Period 1999-2002 } & \multicolumn{4}{|c|}{ Period 2001-2004 } \\
\hline $\begin{array}{c}\text { Pair of Risk } \\
\text { measures } \\
\left(\mathrm{RV}_{1 \mathrm{i}} / \mathrm{RV}_{2 \mathrm{i}}\right)\end{array}$ & $\gamma_{\mathrm{o}}$ & $\gamma_{1}$ & $\gamma_{2}$ & $\operatorname{Adj}-R^{2}$ & $\gamma_{0}$ & $\gamma_{1}$ & $\gamma_{2}$ & Adj- $R^{2}$ \\
\hline$\sigma / \Sigma$ & $\begin{array}{c}0.0032 \\
(4.78)^{* *}\end{array}$ & $\begin{array}{c}0.3480 \\
(2.15) \\
\end{array}$ & $\begin{array}{c}-0.6297 \\
(-2.87) \\
\end{array}$ & 0.421 & $\begin{array}{c}0.0044 \\
(7.27)^{* *}\end{array}$ & $\begin{array}{c}-0.6095 \\
(-3.55) \\
\end{array}$ & $\begin{array}{c}0.6243 \\
(2.87) \\
\end{array}$ & 0.626 \\
\hline$\beta / \beta^{\mathrm{D}}$ & $\begin{array}{l}0.0021 \\
(3.01)\end{array}$ & $\begin{array}{c}-0.0038 \\
(-1.64)\end{array}$ & $\begin{array}{l}-0.0001 \\
(-0.75)\end{array}$ & 0.431 & $\begin{array}{c}0.0047 \\
(8.42)\end{array}$ & $\begin{array}{c}-0.0034 \\
(-1.53)\end{array}$ & $\begin{array}{c}-0.0018 \\
(-0.85)\end{array}$ & 0.673 \\
\hline
\end{tabular}

$* \sigma=$ the standard deviation of returns, $\Sigma=$ the semideviation of returns, $\beta=$ the beta coefficient, and $\beta^{\mathrm{D}}=$ the downside beta.

** $\mathrm{t}$ statistics are included in parentheses. Critical value for a two-sided test at $1 \%$ significant level: 2.58 
Table 7. Estimating the cross-sectional simple linear regression model $\mathbf{M R}_{\mathbf{i}}=\gamma_{\mathbf{0}}+\gamma_{\mathbf{1}} \mathbf{R} \mathbf{V}_{\mathbf{i}}+\mathbf{u}_{\mathrm{i}}$ for individual securities (France)

\begin{tabular}{|c|c|c|c|c|c|c|}
\hline \multicolumn{5}{|c|}{ Period 1999-2002 } & \multicolumn{3}{|c|}{ Period 2001-2004 } \\
\hline $\begin{array}{c}\text { Risk measure } \\
\left(\mathrm{RV}_{\mathrm{j}}\right)^{*}\end{array}$ & $\gamma_{\mathrm{o}}$ & $\gamma_{1}$ & Adj-R & $\gamma_{\mathrm{o}}$ & $\gamma_{1}$ & Adj-R $^{2}$ \\
\hline$\sigma$ & 0.0030 & $-0,0694$ & 0.209 & 0.0069 & -0.1348 & 0.496 \\
& $(4.80)$ & $(-6.58)$ & & $(11.47)^{* *}$ & $(-14.29)$ & \\
\hline$\Sigma$ & 0.0030 & -0.0977 & 0.229 & 0.0071 & -0.1937 & 0.512 \\
& $(5.05)$ & $(-6.98)$ & & $(11.87)$ & $(-14.75)$ & \\
\hline$\beta$ & 0.0005 & -0.0025 & 0.113 & 0.0032 & -0.0068 & 0.345 \\
& $(2.23)$ & $(-4.63)$ & & $(6.60)$ & $(-10.47)$ & \\
\hline$\beta^{\mathrm{D}}$ & 0.0016 & -0.0031 & 0.183 & 0.0058 & -0.0075 & 0.446 \\
& $(3.50)$ & $(-6.08)$ & & $(9.93)$ & $(-12.91)$ & \\
\hline
\end{tabular}

* $\sigma=$ the standard deviation of returns, $\Sigma=$ the semideviation of returns, $\beta=$ the beta coefficient (with respect to CAC-40), and $\beta^{\mathrm{D}}=$ the downside beta.

** $\mathrm{t}$ statistics are included in parentheses. Critical value for a two-sided test at $1 \%$ significant level: 2.58

Table 8. Estimating the cross-sectional simple linear regression model $\mathbf{M R}_{\mathrm{i}}=\gamma_{\mathbf{0}}+\gamma_{1} \mathbf{R V _ { i }}+\mathbf{u}_{\mathrm{i}}$ for 20 portfolios (France)

\begin{tabular}{|c|c|c|c|c|c|c|}
\hline \multicolumn{5}{|c|}{ Period 1999-2002 } & \multicolumn{3}{|c|}{ Period 2001-2004 } \\
\hline $\begin{array}{c}\text { Risk measure } \\
\left(\mathrm{RV}_{\mathrm{j}}\right)^{*}\end{array}$ & $\gamma_{\mathrm{o}}$ & $\gamma_{1}$ & Adj-R & $\gamma_{\mathrm{o}}$ & $\gamma_{1}$ & Adj-R $^{2}$ \\
\hline$\sigma$ & 0.0022 & -0.0976 & 0.499 & 0.0053 & -0.1890 & 0.779 \\
& $(2.98)$ & $(-4.46)$ & & $(6.42)^{* *}$ & $(-8.24)$ & \\
\hline$\Sigma$ & 0.0021 & -0.1290 & 0.476 & 0.0059 & -0.2689 & 0.762 \\
& $(2.95)$ & $(-4.44)$ & & $(6.34)$ & $(-8.08)$ & \\
\hline$\beta$ & 0.0007 & -0.0030 & 0.331 & 0.0038 & -0.0078 & 0.633 \\
& $(2.29)$ & $(-3.23)$ & & $(4.14)$ & $(-5.82)$ & \\
\hline$\beta^{\mathrm{D}}$ & 0.0014 & -0.0034 & 0.419 & 0.0054 & -0.0082 & 0.692 \\
& $(2.15)$ & $(-3.83)$ & & $(5.18)$ & $(-6.61)$ & \\
\hline
\end{tabular}

* $\sigma=$ the standard deviation of returns, $\Sigma=$ the semideviation of returns, $\beta=$ the beta coefficient, and $\beta^{\mathrm{D}}=$ the downside beta.

** $\mathrm{t}$ statistics are included in parentheses. Critical value for a two-sided test at $1 \%$

significance level: 2.58

Table 9. Estimating the cross-sectional simple linear regression model $\mathbf{M R}_{\mathrm{i}}=\gamma_{\mathrm{o}}+\gamma_{1} \mathbf{R} \mathbf{V}_{\mathrm{i}}+\mathbf{u}_{\mathrm{i}}$ for $32 / 41$ portfolios (France)

\begin{tabular}{|c|c|c|c|c|c|c|}
\hline \multicolumn{4}{|c|}{ Period 1999-2002 } & \multicolumn{3}{|c|}{ Period 2001-2004 } \\
\hline $\begin{array}{c}\text { Risk measure } \\
\left(\mathrm{RV}_{\mathrm{j}}\right)^{*}\end{array}$ & $\gamma_{\mathrm{o}}$ & $\gamma_{1}$ & Adj- $\mathrm{R}^{2}$ & $\gamma_{\mathrm{o}}$ & $\gamma_{1}$ & Adj- $^{2}$ \\
\hline$\sigma$ & 0.0023 & -0.0930 & 0.484 & 0.0055 & -0.1719 & 0.694 \\
& $(3.79)$ & $(-5.49)$ & & $(7.57)^{* *}$ & $(-9.59)$ & \\
\hline$\Sigma$ & 0.0022 & -0.1229 & 0.477 & 0.0058 & -0.2426 & 0.682 \\
& $(3.67)$ & $(-5.41)$ & & $(7.45)$ & $(-9.37)$ & \\
\hline$\beta$ & 0.0008 & -0.0032 & 0.398 & 0.0034 & -0.0071 & 0.541 \\
& $(2.31)$ & $(-4.64)$ & & $(4.81)$ & $(-6.94)$ & \\
\hline$\beta^{\text {D }}$ & 0.0014 & -0.0034 & 0.439 & 0.0052 & -0.0077 & 0.631 \\
& $(2.84)$ & $(-5.03)$ & & $(6.74)$ & $(-8.33)$ & \\
\hline
\end{tabular}

$* \sigma=$ the standard deviation of returns, $\Sigma=$ the semideviation of returns, $\beta=$ the beta coefficient, and $\beta^{\mathrm{D}}=$ the downside beta.

$* * \mathrm{t}$ statistics are included in parentheses. Critical value for a two-sided test at $1 \%$

significance level: 2.58 
Table 10. Estimating the cross-sectional simple linear regression model $\mathbf{M R}_{\mathbf{i}}=\gamma_{\mathbf{0}}+\gamma_{1} \mathbf{R} \mathbf{V}_{1 \mathrm{i}}+\gamma_{1} \mathbf{R} \mathbf{V}_{2 \mathrm{i}}+\mathbf{u}_{\mathbf{i}}$ for individual securities (France)

\begin{tabular}{|c|c|c|c|c|c|c|c|c|}
\hline \multicolumn{5}{|c|}{ Period 1999-2002 } & \multicolumn{4}{|c|}{ Period 2001-2004 } \\
\hline $\begin{array}{c}\text { Pair of Risk } \\
\text { measures } \\
\left(\mathrm{RV}_{1 \mathrm{i}} / \mathrm{RV}_{2 \mathrm{i}}\right)\end{array}$ & $\gamma_{\mathrm{o}}$ & $\gamma_{1}$ & $\gamma_{2}$ & $\operatorname{Adj}-R^{2}$ & $\gamma_{o}$ & $\gamma_{1}$ & $\gamma_{2}$ & $\operatorname{Adj}-R^{2}$ \\
\hline$\sigma / \Sigma$ & $\begin{array}{l}0.0027 \\
(4.17)\end{array}$ & $\begin{array}{c}0.1034 \\
(1.51)\end{array}$ & $\begin{array}{c}-0.2553 \\
(2.56) \\
\end{array}$ & 0.235 & $\begin{array}{c}0.0071 \\
(11.79)^{* *}\end{array}$ & $\begin{array}{c}-0.0026 \\
(-0.05)\end{array}$ & $\begin{array}{c}-0.1900 \\
(-2.60)\end{array}$ & 0.510 \\
\hline$\beta / \beta^{\mathrm{D}}$ & $\begin{array}{l}0.0027 \\
(4.64)\end{array}$ & $\begin{array}{c}0.0046 \\
(2.94)\end{array}$ & $\begin{array}{c}-0.0075 \\
(-4.79)\end{array}$ & 0.221 & $\begin{array}{c}0.0061 \\
(9.44)\end{array}$ & $\begin{array}{c}0.0016 \\
(1.07)\end{array}$ & $\begin{array}{c}-0.0090 \\
(-6.19)\end{array}$ & 0.446 \\
\hline
\end{tabular}

$* \sigma=$ the standard deviation of returns, $\Sigma=$ the semideviation of returns, $\beta=$ the beta coefficient, and $\beta^{\mathrm{D}}=$ the downside beta.

** $\mathrm{t}$ statistics are included in parentheses. Critical value for a two-sided test at $1 \%$ significant level: 2.58

Table 11. Estimating the cross-sectional simple linear regression model $\mathbf{M R}_{\mathbf{i}}=\gamma_{0}+\gamma_{1} \mathbf{R V} \mathbf{1 i}_{\mathbf{i}}+\gamma_{1} \mathbf{R} \mathbf{V}_{2 \mathrm{i}}+\mathbf{u}_{\mathrm{i}}$ for 20 portfolios (France)

\begin{tabular}{|c|c|c|c|c|c|c|c|c|}
\hline \multicolumn{5}{|c|}{ Period 1999-2002 } & \multicolumn{4}{|c|}{ Period 2001-2004 } \\
\hline $\begin{array}{c}\text { Pair of Risk } \\
\text { measures } \\
\left(\mathrm{RV}_{1 \mathrm{i}} / \mathrm{RV}_{2 \mathrm{i}}\right)\end{array}$ & $\gamma_{\mathrm{o}}$ & $\gamma_{1}$ & $\gamma_{2}$ & $\operatorname{Adj}-R^{2}$ & $\gamma_{\mathrm{o}}$ & $\gamma_{1}$ & $\gamma_{2}$ & $\operatorname{Adj}-R^{2}$ \\
\hline$\sigma / \Sigma$ & $\begin{array}{c}0.0022 \\
(2.89)\end{array}$ & $\begin{array}{c}-0.865 \\
(-0.33)\end{array}$ & $\begin{array}{c}-0.0147 \\
(-0.04) \\
\end{array}$ & 0.470 & $\begin{array}{c}0.0053 \\
(4.59)^{* *}\end{array}$ & $\begin{array}{r}-0.2177 \\
(-0.75)\end{array}$ & $\begin{array}{l}0.0411 \\
(0.099)\end{array}$ & 0.766 \\
\hline$\beta / \beta^{\mathrm{D}}$ & $\begin{array}{c}0.0021 \\
(2.53)\end{array}$ & $\begin{array}{c}0.0051 \\
(1.29) \\
\end{array}$ & $\begin{array}{c}-0.0085 \\
(-2.12)\end{array}$ & 0.440 & $\begin{array}{c}0.0057 \\
(4.32) \\
\end{array}$ & $\begin{array}{c}0.0029 \\
(0.49)\end{array}$ & $\begin{array}{c}-0.0111 \\
(-1.87)\end{array}$ & 0.678 \\
\hline
\end{tabular}

$* \sigma=$ the standard deviation of returns, $\Sigma=$ the semideviation of returns, $\beta=$ the beta coefficient, and $\beta^{\mathrm{D}}=$ the downside beta.

** $t$ statistics are included in parentheses. Critical value for a two-sided test at $1 \%$ significant level: 2.58

Table 12. Estimating the cross-sectional simple linear regression model $\mathbf{M R}_{\mathbf{i}}=\gamma_{\mathbf{0}}+\gamma_{1} \mathbf{R V} \mathbf{1 i}_{\mathbf{i}}+\gamma_{1} \mathbf{R} \mathbf{V}_{\mathbf{2 i}}+\mathbf{u}_{\mathrm{i}}$ for $32 / 41$ portfolios (France)

\begin{tabular}{|c|c|c|c|c|c|c|c|c|}
\hline \multicolumn{5}{|c|}{ Period 1999-2002 } & \multicolumn{4}{|c|}{ Period 2001-2004 } \\
\hline $\begin{array}{c}\text { Pair of Risk } \\
\text { measures } \\
\left(\mathrm{RV}_{1 \mathrm{i}} / \mathrm{RV}_{2 \mathrm{i}}\right)\end{array}$ & $\gamma_{\mathrm{o}}$ & $\gamma_{1}$ & $\gamma_{2}$ & $\operatorname{Adj}-R^{2}$ & $\gamma_{\mathrm{o}}$ & $\gamma_{1}$ & $\gamma_{2}$ & $\operatorname{Adj}-R^{2}$ \\
\hline$\sigma / \Sigma$ & $\begin{array}{c}0.0024 \\
(3.68)^{* *}\end{array}$ & $\begin{array}{c}-0.1264 \\
(-0.67)\end{array}$ & $\begin{array}{l}0.0427 \\
(0.173)\end{array}$ & 0.467 & $\begin{array}{c}0.0053 \\
(6.37)^{* *}\end{array}$ & $\begin{array}{c}-0.2673 \\
(-1.34)\end{array}$ & $\begin{array}{c}0.1364 \\
(0.48)\end{array}$ & 0.688 \\
\hline$\beta / \beta^{\mathrm{D}}$ & $\begin{array}{c}0.0016 \\
(2.39)\end{array}$ & $\begin{array}{c}0.0011 \\
(0.38)\end{array}$ & $\begin{array}{c}-0.0045 \\
(-1.51)\end{array}$ & 0.423 & $\begin{array}{c}0.0056 \\
(6.14)\end{array}$ & $\begin{array}{c}-0.0040 \\
(-1.15)\end{array}$ & $\begin{array}{c}-0.0116 \\
(-3.30)\end{array}$ & 0.634 \\
\hline
\end{tabular}

* $\sigma=$ the standard deviation of returns, $\Sigma=$ the semideviation of returns, $\beta=$ the beta coefficient, and $\beta^{\mathrm{D}}=$ the downside beta.

** $\mathrm{t}$ statistics are included in parentheses. Critical value for a two-sided test at 1\% significant level: 2.58 